\title{
Nickel and palladium catalyzed Kumada-Tamao-Corriu cross-coupling reactions: scope and recent advances
}

\author{
Adnan A. Dahadha*a and Mohammad M. Aldhoun ${ }^{b}$ \\ ${ }^{a}$ Biotechnology Department, Faculty of Science, Philadelphia University, P. O. Box. 19392, Amman, Jordan \\ ${ }^{b}$ Faculty of Pharmacy, Philadelphia University, P. O. Box. 19392, Amman, Jordan \\ Email: adnan.dahadha chem@yahoo.com
}

Published on line $12-16-2018$

\section{Abstract}

The nickel and palladium catalyzed Kumada-Tamao-Corriu cross-coupling reaction is a powerful method for the formation of carbon-carbon bonds, employed in many large-scale applications in the pharmaceutical and electronic material industries. Kumada cross-coupling is the reaction of an organohalide substrate with a Grignard reagent to produce the corresponding coupled product using a palladium or nickel catalyst. This review covers key developments in Kumada cross-coupling reactions over the past ten years.

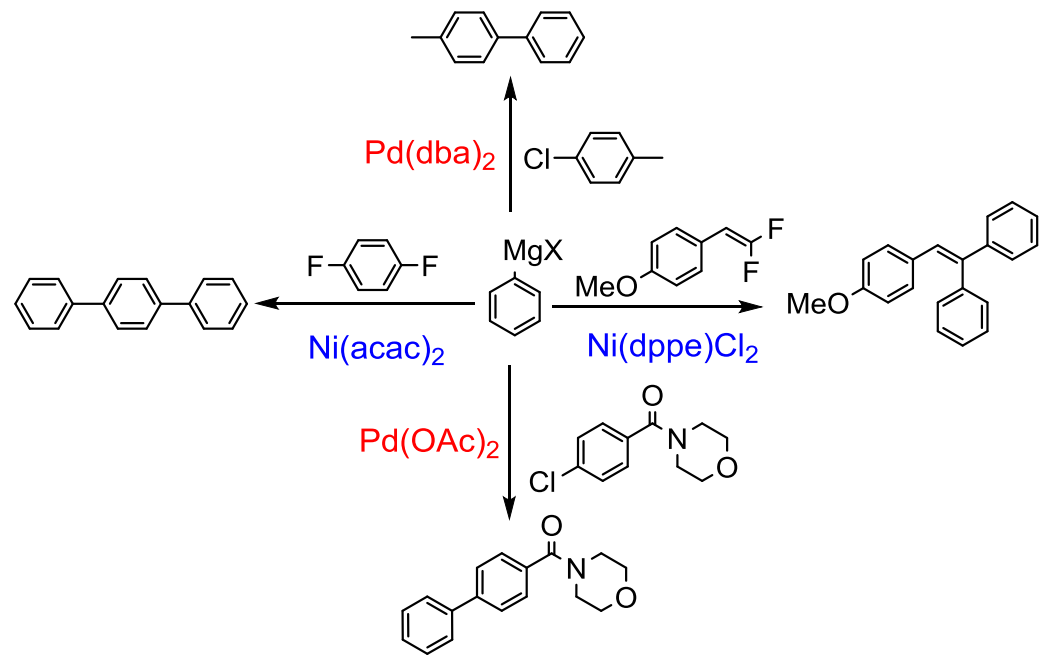

Keywords: Kumada coupling, nickel catalysis, palladium catalysis, Grignard reagents, biaryls 


\section{Table of Contents}

1. Introduction

1.1 Historical review of cross-coupling reactions

1.2 General mechanism of catalytic cross-coupling reactions

2. Metal Catalyzed Kumada Cross-coupling Reactions

2.1 Palladium catalyzed Kumada cross-coupling reactions

2.2 Nickel catalyzed Kumada cross-coupling reactions

3. Conclusions

References

\section{Introduction}

\subsection{Historical review of cross-coupling reactions}

The metal catalyzed cross-coupling reactions of organic compounds by employing various transition metals are a significant technique to form carbon-carbon bonds, enabling the preparation of an enormous structural diversity of complex molecules, essential in the pharmaceutical industry and for preparing organic materials. ${ }^{1}$ Several organometallic nucleophiles based on metals like magnesium, tin and zinc were improved to link with different electrophilic substrates, in the presence of the transition metal catalysts such as palladium, nickel, copper, and iron. Substantial advances were achieved in this field over the past decade. ${ }^{2-6}$ Herein, we give a brief overview of the historical origins of some powerful and common carbon-carbon bond formation via metal catalyzed cross-coupling reactions.

In 1955, Cadiot and Chodkiewicz reported the first copper(I) catalyzed cross-coupling reaction of an alkynyl halide with a terminal alkynyl, providing a single product. ${ }^{7}$ In the same area, at the end of the 1950 s, Eglinton demonstrated an effective method to form carbon-carbon bonds by oxidative coupling of terminal alkynes, using stoichiometric amounts of copper(II) acetate in pyridine. ${ }^{8}$ In $1963, C(s p)-C\left(s^{2}\right)$ bond formation was achieved by Castro and Stephens, through the reaction of a copper(I) acetylide and an aryl halide in pyridine, forming a disubstituted alkyne. ${ }^{9}$

Kumada-Corriu-Tamao cross-coupling reactions were first reported in 1972. The coupling reaction of various Grignard reagents with a wide range of organic halide substrates with catalysis based on palladium and nickel complexes, this protocol opened up a wide scope for the preparation of an enormous variety of organic compounds by carbon-carbon bond formation from different organic halides. ${ }^{10}$ In the same period, Heck formulated the coupling of an unsaturated halide (or triflate) with an alkene with the aid of palladium catalysts to form a substituted alkene; ${ }^{11}$ this extended study culminated in 2010 in the award of the Nobel prize for chemistry, which was shared with Negishi and Suzuki, for the invention and development of this reaction. Japanese chemists have played a distinguished role in the development of coupling reactions, such as the Sonogashira cross-coupling reaction, first reported by Sonogashira, Tohda and Hagihara in 1975, who employed both palladium and copper catalysts simultaneously to form a carbon-carbon bond by the reaction of a terminal alkyne and an aryl or vinyl halide at room temperature, in an aqueous medium. ${ }^{12,13}$

The 1970s provided significant innovations in the field of the catalytic cross-coupling reactions, with important contributions from Corriu, Kumada, Kochi, Murahashi, Sonogashira, Stille, Yamamoto, and Negishi who achieved the palladium catalyzed cross coupling reaction of alkenyl halides with organozinc compounds like alkynylzinc chlorides, to form the corresponding terminal or internal enynes in synthetically useful 
yields. ${ }^{14,15}$ In 1978 , Stille reported a selective and novel protocol to couple acyl chloride substrates with organotin compounds using a palladium catalyst to afford a multitude of ketones. ${ }^{16,17}$ Later, in 1979 , Suzuki designed an effective and novel method for the coupling reaction of organohalides and aryl- or vinyl-boronic acids in the presence of the palladium catalysts with a base to generate a wide spectrum of important organic compounds. ${ }^{18-20}$

In 1988, Hiyama reported an efficient cross-coupling reaction of organosilanes such as allyl-, vinyl-, and ethynylsilanes with organohalides through palladium catalysis to give cross-coupled products. ${ }^{21}$ Organosilanes have gained importance as organometallic reagents because of their high stability, low toxicity, and ease of handling. ${ }^{22,23}$ The cross-coupling between thioesters and organozinc halides using a palladium or nickel catalyst under mild reaction conditions to produce ketones chemoselectively was discovered in 1998 by Fukyama. ${ }^{24,25}$ Still more recently, in 2000, Srogl and Liebeskind developed an efficient versatile methodology for the synthesis of ketones by palladium-catalyzed cross-coupling reaction of thioester compounds and boronates under base-free conditions. ${ }^{26}$

\subsection{General mechanism of catalytic cross coupling reactions}

Catalytic cross-coupling reactions consist in the coupling of nucleophiles such as Grignard reagents, boronic acids, organozinc or organotin compounds with electrophiles like alkyl or aryl halides, by using transition metal complexes as catalysts. In general, the metal catalyzed coupling reaction is believed to consist of three major steps: oxidative addition, transmetalation, and reductive elimination. The catalytic cycle starts with oxidative addition of the carbon-halogen bond to the zerovalent metal complex $L_{n} M(0)$ to form a $L_{n} M(I I)$ complex, where $L_{n}$ represents the mono or bidentate ligands. Then, transmetalation via the $R$ group of the nucleophile replaces the halide anion on the $\mathrm{M}(\mathrm{II})$ complex to produce diorganometal intermediates. An isomerization process in the latter is essential to bring the two organic residues next to each other in cis position of a square planar intermediate. Finally, reductive elimination affords the corresponding coupled product and to regenerate the catalytically active species as illustrated in Scheme $1 .^{1}$

The nature of the ligands in metal complexes play a remarkable role in oxidative addition processes, as their function is to support the formation of a coordinatively unsaturated species of sufficient reactivity. ${ }^{27,28}$ Actually, the zerovalent metal may be created in situ in two ways, ligand dissociation from a metal complex with a higher coordination number, or reduction of stable divalent metal complexes via organometallic species such as a Grignard reagent. ${ }^{29,30}$

Beginning in the 1970s, nickel complexes have been extensively used in cross-coupling reactions. ${ }^{31,32}$ Since Kumada reported the coupling reaction of Grignard reagents and organohalides using nickel-phosphine complexes, a wide diversity of coupling reactions have been developed for synthetic chemistry. ${ }^{33}$ Palladium and nickel complexes possess excellent catalytic activity and high functional group tolerance in these reactions. $^{34}$ 


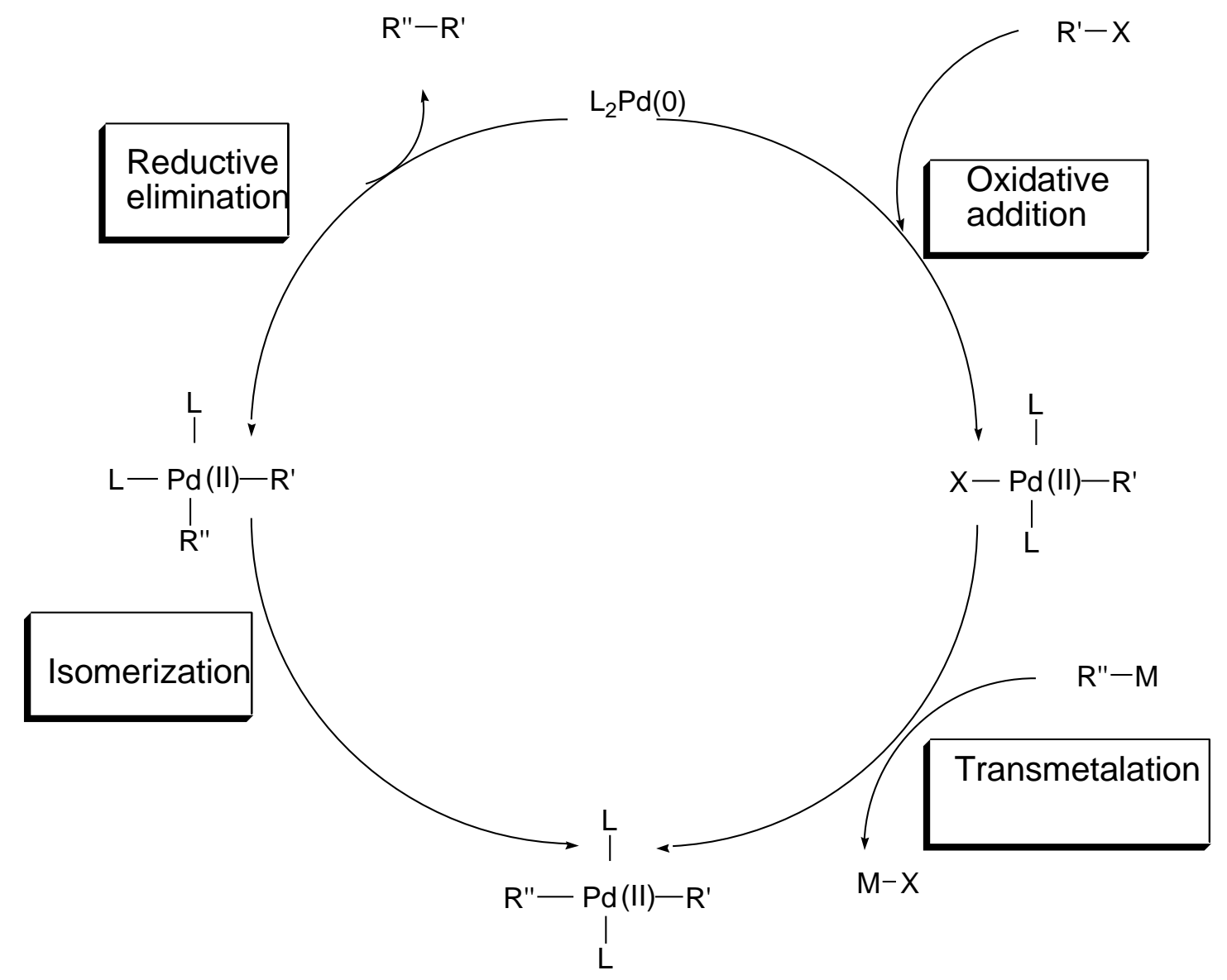

Scheme 1. The general mechanism of metal catalyzed cross-coupling reactions.

Chelating phosphine ligands are usually effective for use in metal catalyzed cross-coupling reactions due to their functional promotion of both the oxidative addition and reductive elimination processes. ${ }^{35}$ Phosphine ligands with high electron density increase the reactivity of metal center towards oxidative addition, and their bulkiness facilitates the formation of the coordinatively unsaturated species as well as the reductive elimination. ${ }^{36,37}$

\section{Metal Catalyzed Kumada-Tamao-Corriu Cross-coupling Reactions}

In this review, we classify the metal-catalyzed Kumada coupling reactions according to the metal present in the catalyst. We therefore discuss two main categories, the palladium catalyzed and the nickel catalyzed crosscoupling reactions.

\subsection{Palladium catalyzed Kumada-Tamao-Corriu cross coupling reactions}

The nickel-phosphine complex catalyzed Kumada cross-coupling reaction of Grignard reagents with alkyl, vinyl or aryl halides, was first reported in 1972. In the same year, Corriu independently demonstrated the coupling reaction of $\beta$-bromostyrene with phenylmagnesium bromide to afford trans-stilbene in the presence of $\mathrm{Ni}(\mathrm{acac})_{2}$ as an active catalyst. ${ }^{1,10}$ The palladium-catalyzed Kumada coupling was first reported by Murahashi in $1975 .^{38}$ Typically, the palladium complex has an exceptional catalytic activity in Kumada cross-coupling, which is mainly attributed to its tendency to undergo a two-electron transfer process that is required in the coupling reaction mechanism. In addition, palladium complexes are generally tolerant to a wide range of functional groups. $^{39,40}$ 
Alkyl halides are often inactive substrates for metal catalyzed cross-coupling reactions because of their reluctance to undergo oxidative addition, and metal alkyl intermediates are prone to induce unproductive $\beta$-hydride eliminations. ${ }^{41,42}$ Nevertheless, significant advances have been accomplished in this field in recent years and carbon-carbon bonds can now be formed by cross-coupling reactions of unactivated alkyl halides and Grignard reagents by exploiting palladium complexes as effective catalysts. ${ }^{43-45}$ The use of unactivated aryl chlorides as substrates in cross-coupling reactions proved to be difficult while their low cost and wide availability makes them a highly attractive substrate class. ${ }^{46}$ Recently, palladium complexes have been employed to catalyze the cross-coupling reaction of Grignard reagents with unactivated aryl chloride substrates. $^{47,48}$

Huang and Nolan reported some successful Kumada cross-coupling reactions in the presence of the aryl chloride substrates (Scheme. 2). ${ }^{49}$ Using $\mathrm{Pd}(0)$ or $\mathrm{Pd}(\mathrm{II})$ in combination with an imidazolium chloride salt as an effective preligand proved useful in this case. As an example, the reaction of 4-chlorotoluene 1 with phenylmagnesium bromide 2 in the presence of tris(dibenzylideneacetone)dipalladium(0) and a 1,3-bis-(2,6diisopropylphenyl)imidazolium salt as the catalyst system provided the desired product 4-phenyltoluene $\mathbf{3}$ in $99 \%$ yield in THF at $80{ }^{\circ} \mathrm{C}$. Building upon this protocol, some of the electron rich aryl chloride substrates such as $4-\mathrm{MeC}_{6} \mathrm{H}_{4}-\mathrm{Cl}, 4-\mathrm{MeOC}_{6} \mathrm{H}_{4}-\mathrm{Cl}, 2$, 5- $\mathrm{Me}_{2} \mathrm{C}_{6} \mathrm{H}_{3}-\mathrm{Cl}, 4-\mathrm{HOC}_{6} \mathrm{H}_{4}-\mathrm{Cl}$, and 2,6- $\mathrm{Me}_{2} \mathrm{C}_{6} \mathrm{H}_{3}-\mathrm{Cl}$ afforded the corresponding cross-coupled products in excellent yields (up to 99\%). The imidazolium salt derivatives served as precursors for bulky NHC-type donor ligands which could facilitate the oxidative addition of aryl chlorides through their electron-donating properties while their bulk somehow also accelerates the reductive elimination process.

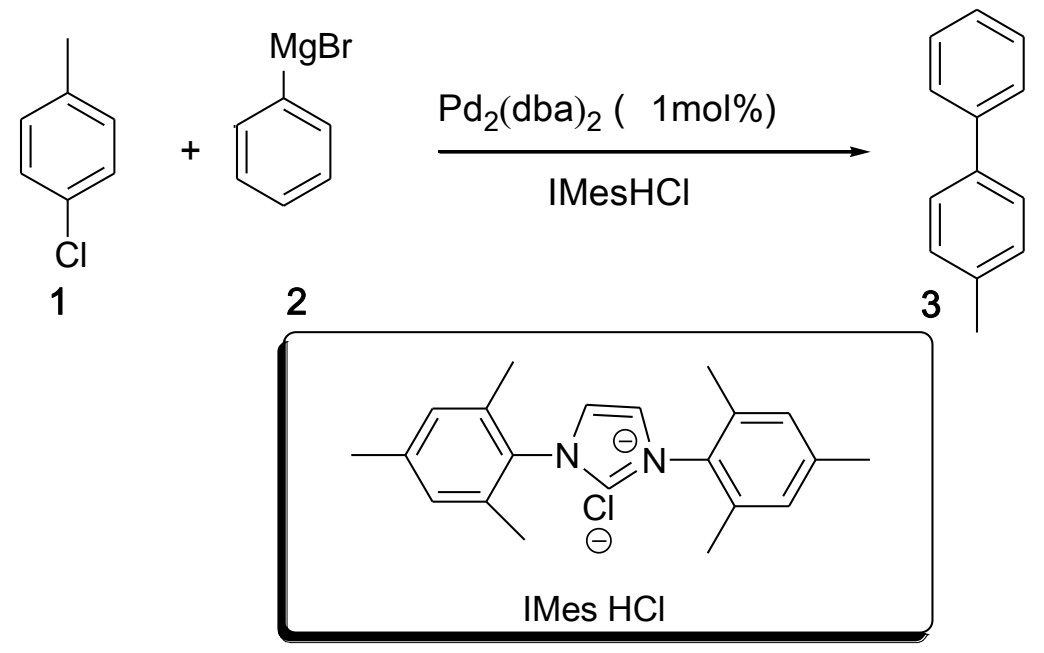

Scheme 2. Cross-coupling of chlorotoluene with phenylmagnesium bromide.

The Kumada cross-coupling reactions are relatively limited in scope by the incompatibility of Grignard reagents with particular functional groups, such as ester, amide, cyano, amino, or alkyl halides. ${ }^{50,51}$ On the other hand, Grignard reagents remain desirable organometallic coupling nucleophiles in Kumada couplings, owing to the ease of their preparation and the commercially availability of many representatives. The modification of the functional group tolerance of the Grignard reagents under the normal Kumada coupling reaction conditions would have a significant impact on the general applicability of this carbon-carbon bond formation. Remarkably, Knochel and co-workers have improved practical methods for the synthesis at very low temperatures of Grignard reagents carrying sensitive functional groups. ${ }^{52,53}$ Recently, the catalytic activity 
of metal complexes based on palladium, nickel and iron have been developed for an efficacious coupling reaction of functionalized Grignard reagents and various substrates under very mild reaction conditions. ${ }^{54}$ In 2007, Martin and Buchwald reported an efficient protocol for the cross-coupling reaction of aryl iodides and aryl Grignard reagents with a variety of functional groups at low temperatures, catalyzed by $\mathrm{Pd}(\mathrm{dba})_{2}$, giving very good yields of coupled products (Scheme 3). ${ }^{55}$

$$
\mathrm{Ar}^{1} \mathrm{MgX}+\mathrm{Ar}^{2} \mathrm{I} \underset{\substack{\text { Toluene, }-20^{\circ} \mathrm{C} \\ \text { under Argon } \\ 6-12 \mathrm{~h}}}{\mathrm{Pd}(\mathrm{dba})_{2}(2 \mathrm{~mol} \%)} \rightarrow \mathrm{Ar}^{1}-\mathrm{Ar}^{2}
$$

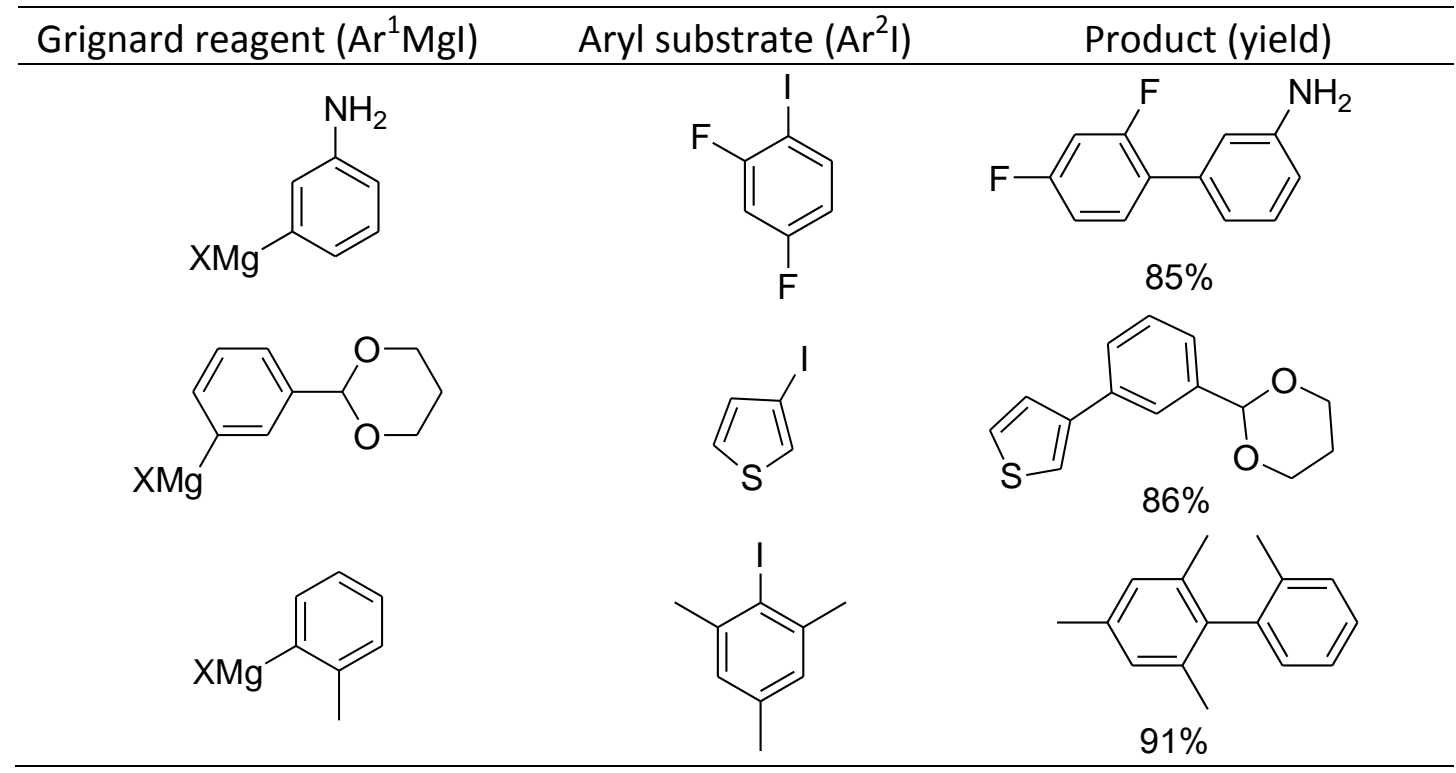

Scheme 3. Some coupling reactions of aryl magnesium halides and aryl iodides.

In 2014, Lipshutz et al. developed a method to construct carbon-carbon bonds by cross-coupling reaction of the functionalized Grignard reagents bearing sensitive functionalities like ester, cyano or halogens and (2bromovinyl)benzene substrate at room temperature, using an effective low Pd-loading catalyst to produce the corresponding functionalized alkenes (Scheme 4$).{ }^{56}$ With the help of the mixed catalyst system including tetramethylethylenediamine (TMEDA) and the bidentate phosphine ligand DPEPhos L, orthobromophenylmagnesium chloride, prepared through halogen-metal exchange, was successfully cross coupled at room temperature affording the alkenes 6 a with $85 \%$ yield. Nitrile and ester functions are fully tolerated, ${ }^{57}$ whereas these functional groups are normally incompatible with the Grignard reagents at room temperature, therefore $\mathbf{6 b}$ and $\mathbf{6 c}$ could be prepared in good yields without by-products in the cross-coupling reaction. 


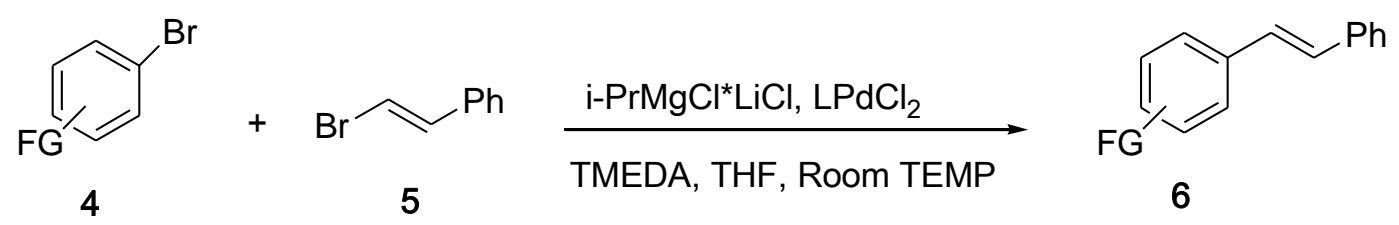

$\mathrm{FG}=\mathrm{F}, \mathrm{Cl}, \mathrm{CN}, \mathrm{EtO}_{2} \mathrm{C}$

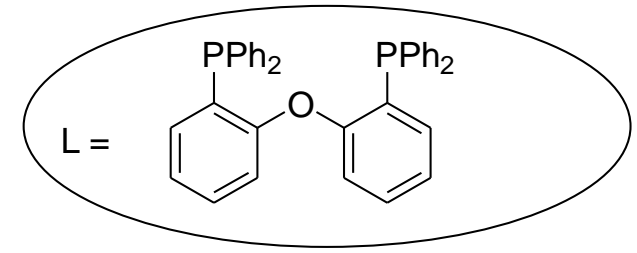<smiles>P/C=C/c1ccccc1Br</smiles>

$6 a, 85 \%$<smiles>N#Cc1c(F)cccc1/C=C/c1ccccc1</smiles>

$6 \mathrm{~b}, 87 \%$<smiles>CCOC(=O)c1ccc(/C=C/c2ccccc2)cc1</smiles>

Scheme 4. Pd-catalyzed cross coupling reaction of alkenyl halides with aryl Grignard reagents.

Most of the studies related to metal catalyzed cross-coupling reactions have focused on expanding the scope of $\mathrm{Pd}$-catalyzed Kumada-Corriu-Tamao cross-coupling reactions in terms of including highly functionalized Grignard reagents, functionalized substrates and a wide range of reaction temperatures. In 2016, Newman and co-workers reported chemoselective Pd-catalyzed Kumada coupling reaction of functionalized aryl chlorides or functionalized chloroheteroarene substrates with phenylmagnesium bromide. $^{58}$ In this optimized cross-coupling methodology, the Grignard reagent $\mathrm{PhMgBr}$ was added over the duration of the reaction by use of a syringe pump to a mixture of $3 \mathrm{~mol} \% \mathrm{Pd}(\mathrm{OAc})_{2}$ and 1.2 equivalents of a substrate at $50{ }^{\circ} \mathrm{C}$, affording the desired product in high chemoselectivity (Scheme 5). Thus, adding the Grignard reagent dropwise to a substrate over the duration of the reaction time to prevent undesired side reactions with sensitive functional groups in the substrates, ensured a smooth conversion. In Newman's research, the addition rate of the Grignard reagent and the temperature were carefully optimized to be as mild as possible to increase the coupling yields (9a-9e).

$$
\begin{array}{cccc}
\mathrm{Ar}-\mathrm{Cl} & +\mathrm{PhMgBr} & \mathrm{Pd}(\mathrm{OAC})_{2}(3 \mathrm{~mol} \%) & \mathrm{Ar}-\mathrm{Ph} \\
\mathbf{7} & \mathbf{8} & \mathrm{THF}, 50{ }^{\circ} \mathrm{C}, 60 \mathrm{~min} & 9
\end{array}
$$<smiles>N#Cc1cccc(Cl)c1</smiles><smiles>N#Cc1ccccc1Cl</smiles><smiles>O=C(c1ccc(Cl)cc1)N1CCOCC1</smiles><smiles>Clc1ccc(-n2ccnc2)cc1</smiles><smiles>CNCCN</smiles><smiles>N#Cc1cccc(-c2ccccc2)c1</smiles><smiles>N#Cc1ccccc1-c1ccccc1</smiles><smiles>O=C(c1ccc(-c2ccccc2)cc1)N1CCOCC1</smiles>

9 a, $89 \%$
$9 b, 84 \%$<smiles>c1ccc(-c2ccc(-n3ccnc3)cc2)cc1</smiles>

9d, $80 \%$<smiles>c1ccc(-c2ccc(-c3cnccn3)cc2)cc1</smiles>

9c, $94 \%$
$\mathrm{Ph}^{-}$

$9 e, 81 \%$

Scheme 5. Pd-catalyzed couplings of functionalized aryl chlorides with $\mathrm{PhMgBr}$. 
Alkenyl fluorides and aryl fluorides were considered to be inappropriate coupling partners in crosscoupling reactions because of the low reactivity for oxidative addition. ${ }^{59}$ Recently, the use of alkenyl fluorides as electrophiles in Kumada cross coupling reactions have attracted much attention. In the presence of a catalytic quantity of a palladium catalyst, the alkenyl fluoride 1-(2,2-difluorovinyl)-4-methoxybenzene (10) reacted with 2.4 equiv of methylmagnesium chloride $\mathbf{1 1}$ under appropriate conditions to give coupling product 12 in high selectivity. This successful cross coupling reaction was described by Cao and his group in $2014{ }^{60}$ However, $\mathrm{Pd}\left(\mathrm{PPh}_{3}\right)_{4}$ was found to be the most effective amongst other Pd catalysts as indicated in Scheme 6 (entries 1-3, 5), whereas the use of $\mathrm{Pd}_{2}(\mathrm{dba})_{3}$ gave the cross coupled product in a low yield (entry 4). $\mathrm{Pd}\left(\mathrm{PPh}_{3}\right)_{4}$ clearly played an essential role in cleaving the reluctant $\mathrm{C}-\mathrm{F}$ bond to facilitate the oxidative additive process. It has an exceptional catalytic activity for the Kumada cross-coupling reaction of the fluoroalkene substrate $\mathbf{1 0}$ and functions well with different Grignard reagents 13 to provide the corresponding coupled products in high yields (14a-14d) (Scheme 7).

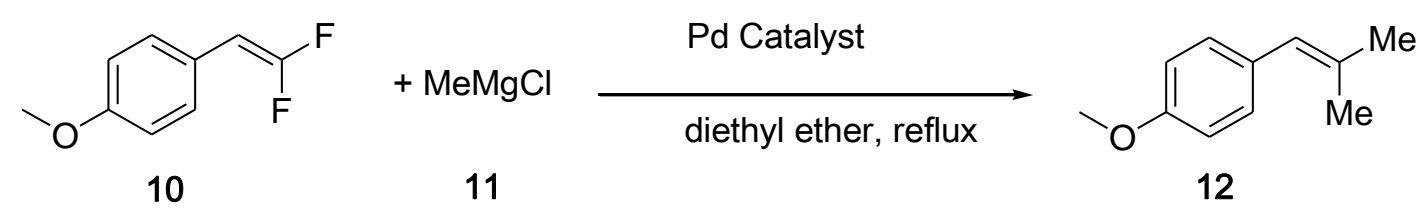

\begin{tabular}{|c|c|c|}
\hline Entry & Catalyst & Yield (\%) \\
\hline 1 & $\mathrm{PdCl}_{2}(\mathrm{dppf})$ & 0 \\
\hline 2 & $\mathrm{PdCl}_{2}$ (dppe) & 0 \\
\hline 3 & $\mathrm{PdCl}_{2}(\mathrm{dppb})$ & 3 \\
\hline 4 & $\mathrm{Pd}_{2}(\mathrm{dba})_{3}$ & 28 \\
\hline 5 & $\mathrm{Pd}\left(\mathrm{PPh}_{3}\right)_{4}$ & 95 \\
\hline
\end{tabular}

Scheme 6. Palladium catalyzed cross-coupling reaction of 1-(2, 2-difluorovinyl)-4-methoxybenzene and methylmagnesium chloride for the synthesis of 1-methoxy-4-vinylbenzene.

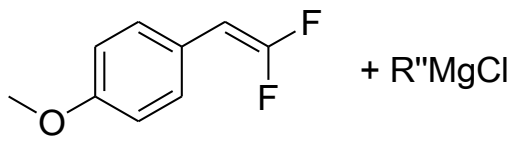

10

13

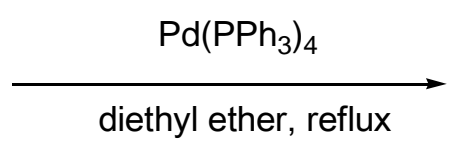<smiles>COc1ccc(C=C(Br)Br)cc1</smiles>

14

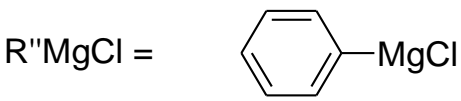<smiles>ClCCc1ccccc1</smiles><smiles>Cl[Mg]c1ccc(I)cc1</smiles><smiles>Fc1ccc(CCl)cc1</smiles><smiles>COc1ccc(C=C(C)C)cc1</smiles>

$14 \mathrm{a}, 82 \%$<smiles>COc1ccc(C=C(c2ccccc2)c2ccccc2)cc1</smiles>

14 b, $87 \%$<smiles>COc1ccc(C=C(c2ccc(C)cc2)c2ccc(C)cc2)cc1</smiles><smiles>COc1ccc(C=C(c2ccc(F)cc2)c2ccc(F)cc2)cc1</smiles>

Scheme 7. $\mathrm{Pd}\left(\mathrm{PPh}_{3}\right)_{4}$-catalyzed cross-coupling reaction of 1-(2,2-difluorovinyl)-4-methoxybenzene and various Grignard reagents. 
Porphyrins are composed of four modified pyrrole subunits connected by methine bridges. Porphyrin derivatives are widely used in the preparation of catalysts, pharmaceuticals, and other materials. ${ }^{61}$ Takanami et al. developed a powerful palladium-catalyzed Kumada cross-coupling reaction of bromoporphyrin substrates and silylmethyl Grignard reagents to provide silylmethyl-substituted porphyrins. ${ }^{62}$ They then described conversions of the versatile silylmethyl groups into other functionalities, including alkoxymethyl, fluoromethyl, alkenyl groups, and elongated alkyl chains. Coupling of 5-bromo-10,20-diphenylporphyrin 15 with (tri-isopropylsilyl)methylmagnesium chloride using $\mathrm{Pd}_{2}(\mathrm{dba})_{3}$ catalyst at $60{ }^{\circ} \mathrm{C}($ Scheme 8$)$, the desired product 15 a was obtained in $>85 \%$ yields. Likewise, the direct conversion of the dibromoporphyrin 16 into bis(silylmethyl)-substituted porphyrins 16 a was achieved in very good yield (Scheme 9).

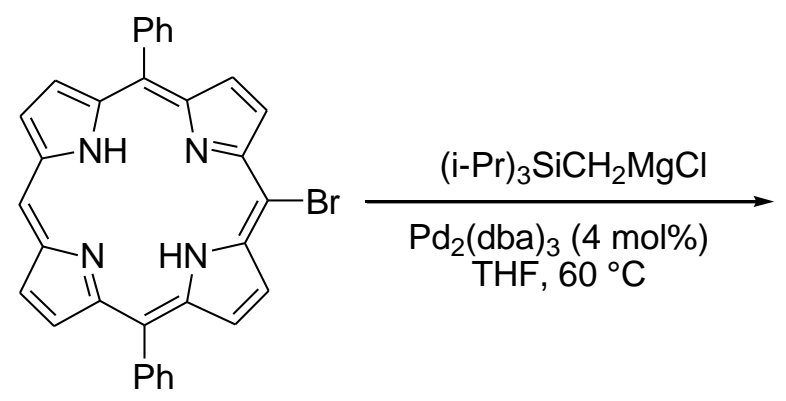

15

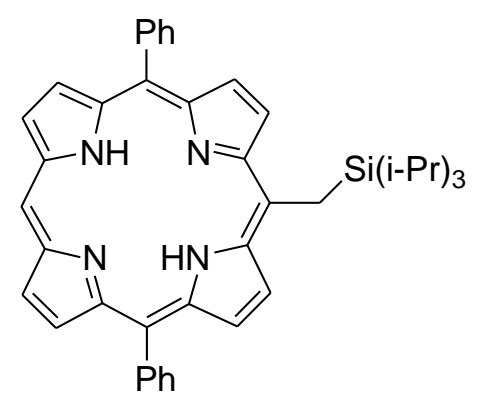

15a, $87 \%$

Scheme 8. Pd catalyzed Kumada cross-coupling of 5-bromo-10,20-diphenylporphyrin with [(tri-isopropylsilyl)methyl]magnesium chloride.

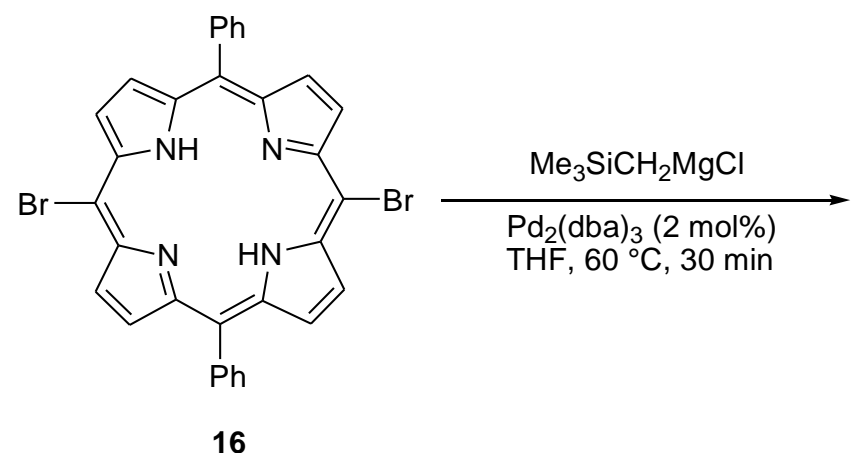

16

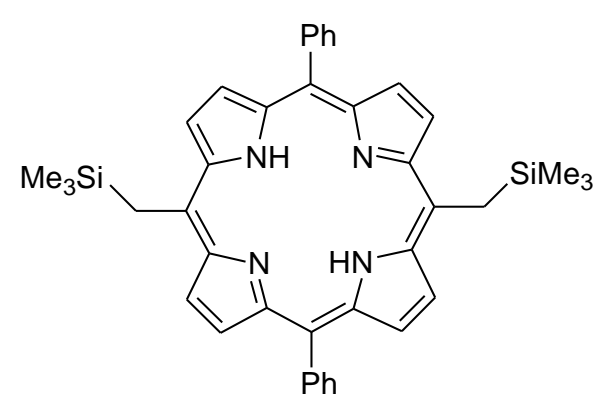

$16 a, 82 \%$

Scheme 9. Preparation of bis(trimethylsilylmethyl)porphyrin.

These silylmethylporphyrins are advantageous as building blocks in the synthesis of more complex porphyrin systems. Indeed, the trimethylsilylmethylporphyrin 17 was treated with a strong oxidant like 2,3dichloro-5,6-dicyanobenzoquinone (DDQ) in THF at a lower temperature $\left(25^{\circ} \mathrm{C}\right)$ to produce hydroxymethylporphyrin $\mathbf{1 8}$ (Scheme 10).

When the oxidation was run in methanol instead, methoxy-substituted product 19 was obtained. Fluoromethyl-substituted porphyrin 20 was formed by DDQ-oxidation of 18 in the presence of DAST [N, Ndiethylaminosulfur trifluoride] as a fluoride ion source. The oxidation of silylmethylporphyrin with an excess of $\mathrm{DDQ}$ in a mixed solvent system $\left(\mathrm{THF} / \mathrm{CH}_{3} \mathrm{CN} /\right.$ water $\left.=1: 1: 5\right)$ at $60{ }^{\circ} \mathrm{C}$ in contrast gave the corresponding formylporphyrin 21. 


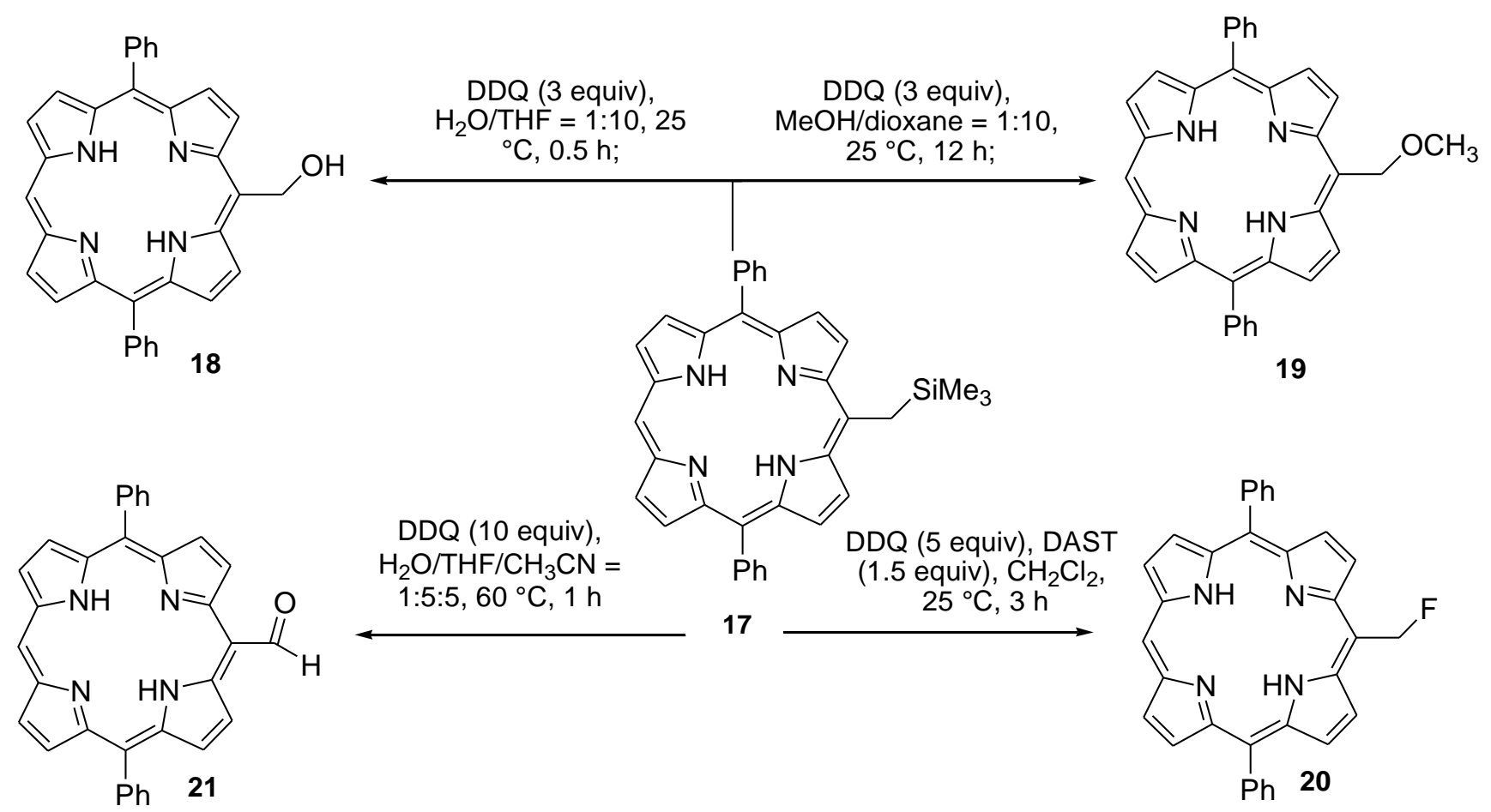

Scheme 10. Transformation of the silylmethyl group of a porphyrin.

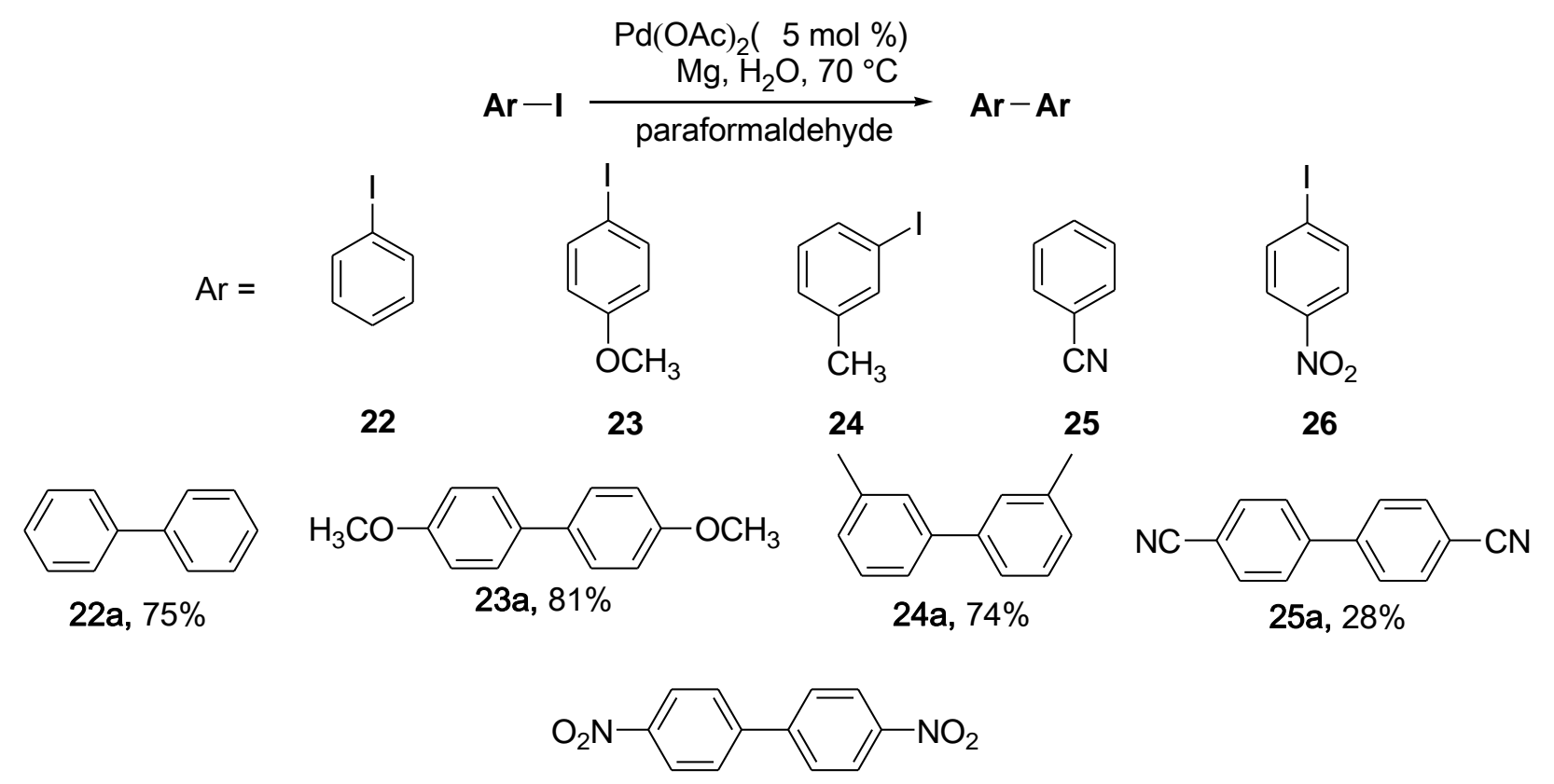

$26 a, 39 \%$

Scheme 11. Homocouplings of aryl halides in water.

Normally, all metal catalyzed Kumada cross-coupling reactions take place under inert and anhydrous conditions. Water not only reacts with Grignard reagents to convert them into the corresponding hydrocarbons but its presence also prevents the formation of the Grignard reagent. ${ }^{63-65}$ For the first time, in 2015, Lipshutz et al. successfully achieved the palladium catalyzed Kumada cross-coupling reactions in 
the presence of water. ${ }^{66}$ Coupled symmetrical/unsymmetrical biaryl products were obtained by mixing aromatic halides, a catalytic quantity of $\mathrm{Pd}(\mathrm{II})$ and excess magnesium metal in water at $70{ }^{\circ} \mathrm{C}$. However, paraformaldehyde as an additive is necessary for symmetrical coupling (homocoupling) and aqueous formalin for unsymmetrical coupling (heterocoupling). Aryl iodides underwent Pd catalyzed Kumada cross-coupling reactions in aqueous conditions to produce homocoupled substituted biaryl (Scheme 11). Consequently, aryl iodide substrates with donor groups $(\mathbf{2 3}, \mathbf{2 4})$ afforded good yields of the biaryl products $23 \mathbf{3}, \mathbf{2 4 a}$, but the electron deficient substrates 25, 26 produced modest to poor yields. On the other hand, heterocoupling reactions of aryl iodides were carried out in an aqueous medium to give modest yields of unsymmetrical biaryl products 27a-31a (Scheme 12). However, when Pd was replaced with $\mathrm{Ni}$, the homo or hetero-coupling products were not observed.

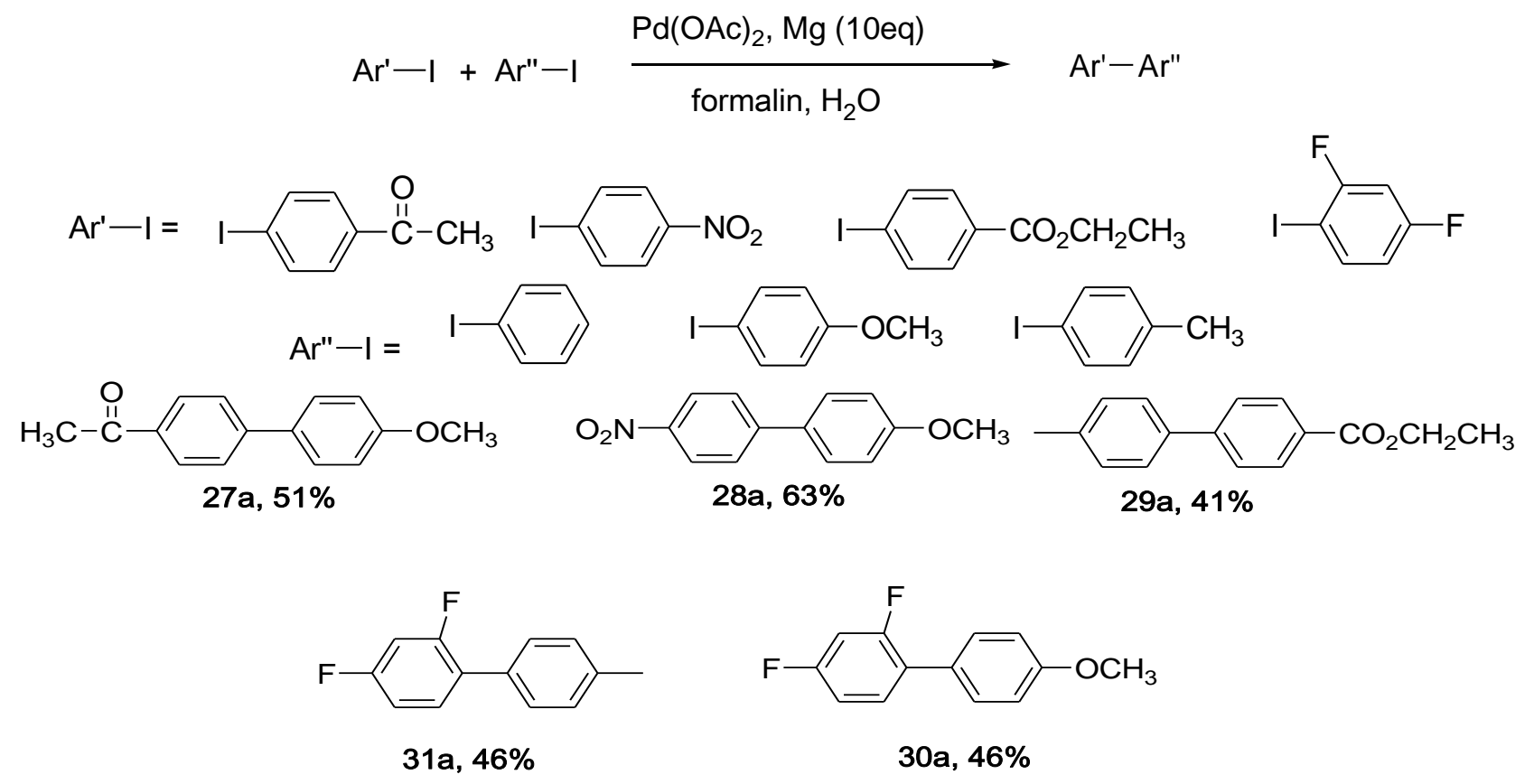

Scheme 12. Cross couplings of aryl halides in water.

\subsection{Nickel catalyzed Kumada-Tamao-Corriu cross-coupling reactions}

In 1972, Kumada, Tamao and Corriu independently reported an excellent method for the formation of carboncarbon bonds by nickel-catalyzed cross-coupling reactions of a broad spectrum of Grignard reagents and organohalide substrates. ${ }^{10}$ In 2011, Wang and Liu developed a coupling reaction of aryl chlorides and aryl or heteroaryl Grignard reagents through nickel-bonded pincer ligands as promising catalysts to afford the coupled products in excellent yields (Scheme 13). ${ }^{67}$ In this way even deactivated aryl chloride substrates, such as $p-\mathrm{Me}_{2} \mathrm{NC}_{6} \mathrm{H}_{4} \mathrm{Cl}$ and $p-\mathrm{MeOC}_{6} \mathrm{H}_{4} \mathrm{Cl}$ reacted effectively with $p-\mathrm{MeC}_{6} \mathrm{H}_{4} \mathrm{MgBr}$ at room temperature by using the complex 32, providing a high yield of the corresponding coupled products (entries 1-4). Otherwise, the use of $0-\mathrm{MeOC}_{6} \mathrm{H}_{4} \mathrm{Cl}$ as the substrate furnished the product is about $68 \%$ yield (entry 6), possibly due to steric hindrance. The coupling reaction of 2-chloropyridine and an aryl Grignard reagent was also achieved in high yield by using 33 as catalyst (entry 5 ).

It has been emphasized that amido pincer nickel complexes are effective catalysts for Kumada crosscoupling reactions. In 2013, Wang et al. have continued to spend efforts to synthesize a new amido pincer nickel complexes, such as complex $34{ }^{68}$ Cross-coupling reaction of $4-\mathrm{MeOC}_{6} \mathrm{H}_{4} \mathrm{Cl}$ and $4-\mathrm{MeC}_{6} \mathrm{H}_{4} \mathrm{MgBr}$ was performed by $\mathbf{3 4}$ under mild conditions with a good catalytic activity (Scheme 14). The catalyst 34 was also 
used as to effect the coupling reaction of 1-chloro-2-methyl-1-propene with substituted aryl magnesium bromide giving the desired products in 60-97\% yields.
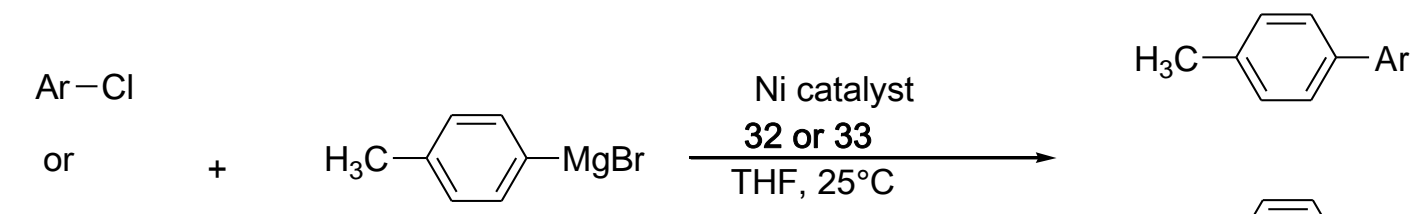

Het-Aryl_- Cl

32 or 33
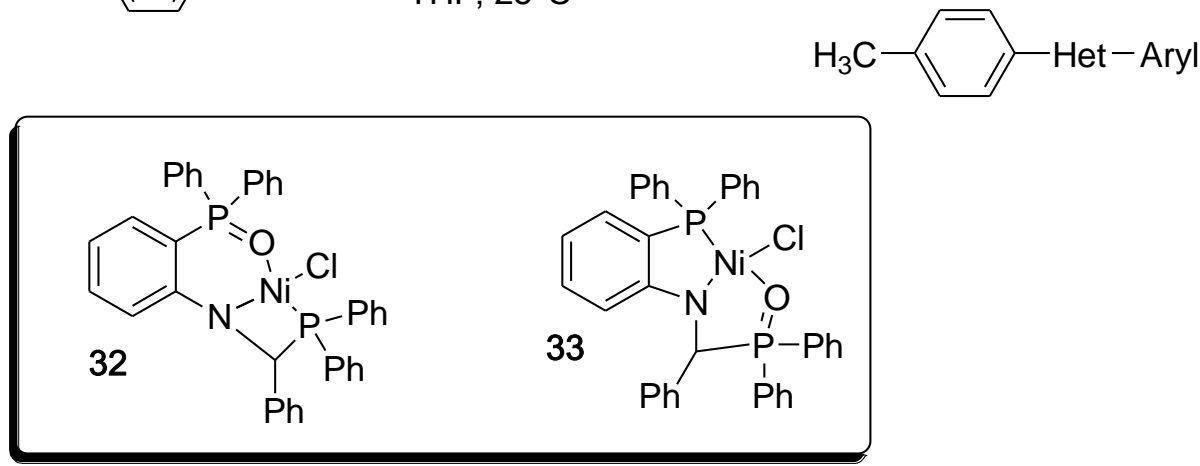

\begin{tabular}{|c|c|c|c|c|c|c|c|}
\hline entry & $\mathrm{ArCl}$ or HetarCl & catalyst & yield \% & entry & $\mathrm{ArCl}$ or HetarCl & catalyst & yield \% \\
\hline 1 & $-\mathrm{CH}_{3}$ & 32 & 97 & 4 & $-\mathrm{OCH}_{3}$ & 32 & 93 \\
\hline 2 & $\mathrm{CH}_{3}$ & 32 & 98 & 5 & & 33 & 99 \\
\hline 3 & $-\mathrm{CN}$ & 32 & 99 & 6 & & 32 & 68 \\
\hline
\end{tabular}

Scheme 13. Some coupling reactions of aryl chloride or heteroaryl chlorides with aryl Grignard reagents catalyzed by amido pincer nickel complexes, 32 or 33.
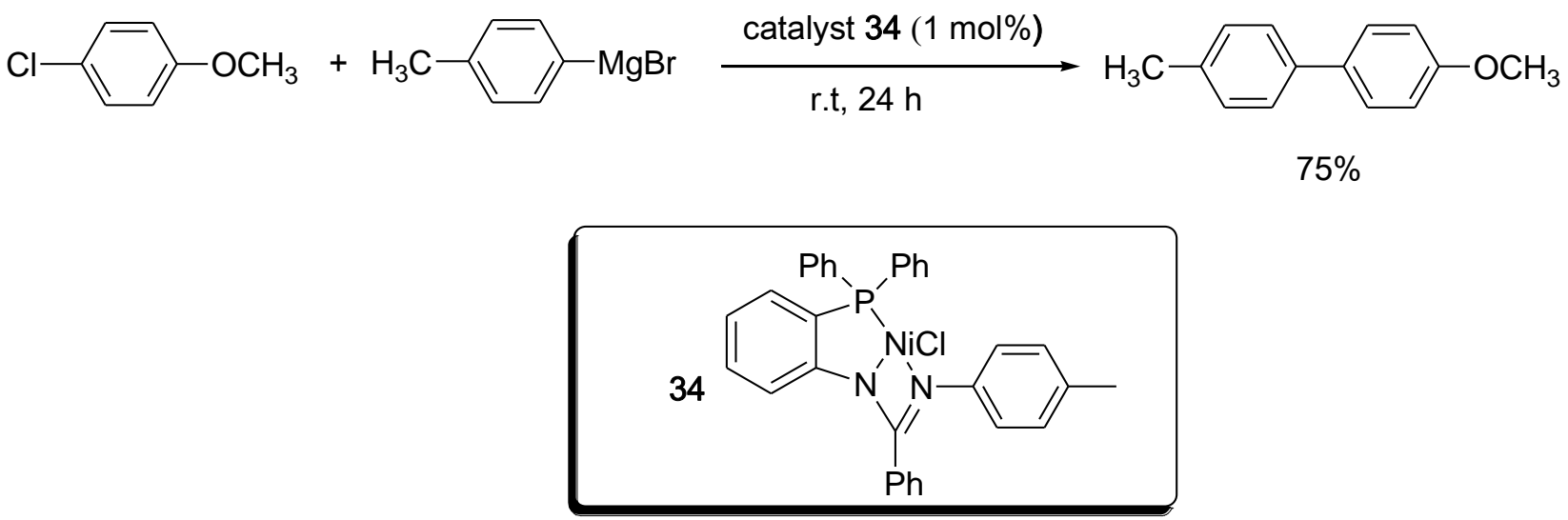

Scheme 14. Cross-coupling reaction of 4- $\mathrm{MeOC}_{6} \mathrm{H}_{4} \mathrm{Cl}$ and 4- $\mathrm{MeC}_{6} \mathrm{H}_{4} \mathrm{MgBr}$ with amido pincer nickel catalyst 34.

The nature of the Grignard reagent and the catalyst loading have a powerful effect on the efficiency of this reaction. Higher catalyst loading may promote an increase in the reaction yield (Scheme 15). Electron rich 
Grignard reagents such as 4- $\mathrm{MeOC}_{6} \mathrm{H}_{4} \mathrm{MgBr}$ and 4- $\mathrm{Me}_{2} \mathrm{NC}_{6} \mathrm{H}_{4} \mathrm{MgBr}$ reacted efficiently with vinyl chloride with 2 mol\% catalyst loading of $\mathbf{3 4}$, furnishing relatively high yields.

\begin{tabular}{ccc} 
& \\
& & \\
\hline $\mathrm{R}$ & Amount catalyst 34 & yield \% \\
$\mathrm{Me}$ & 1 & \\
$\mathrm{Me}$ & 2 & 60 \\
$\mathrm{MeO}$ & 1 & 77 \\
$\mathrm{MeO}$ & 2 & 93 \\
$\mathrm{Me}{ }_{2} \mathrm{~N}$ & 1 & 97 \\
\hline
\end{tabular}

Scheme 15. Reaction of 1-chloro-2-methyl-1-propene with aryl Grignard reagents catalyzed by 34.
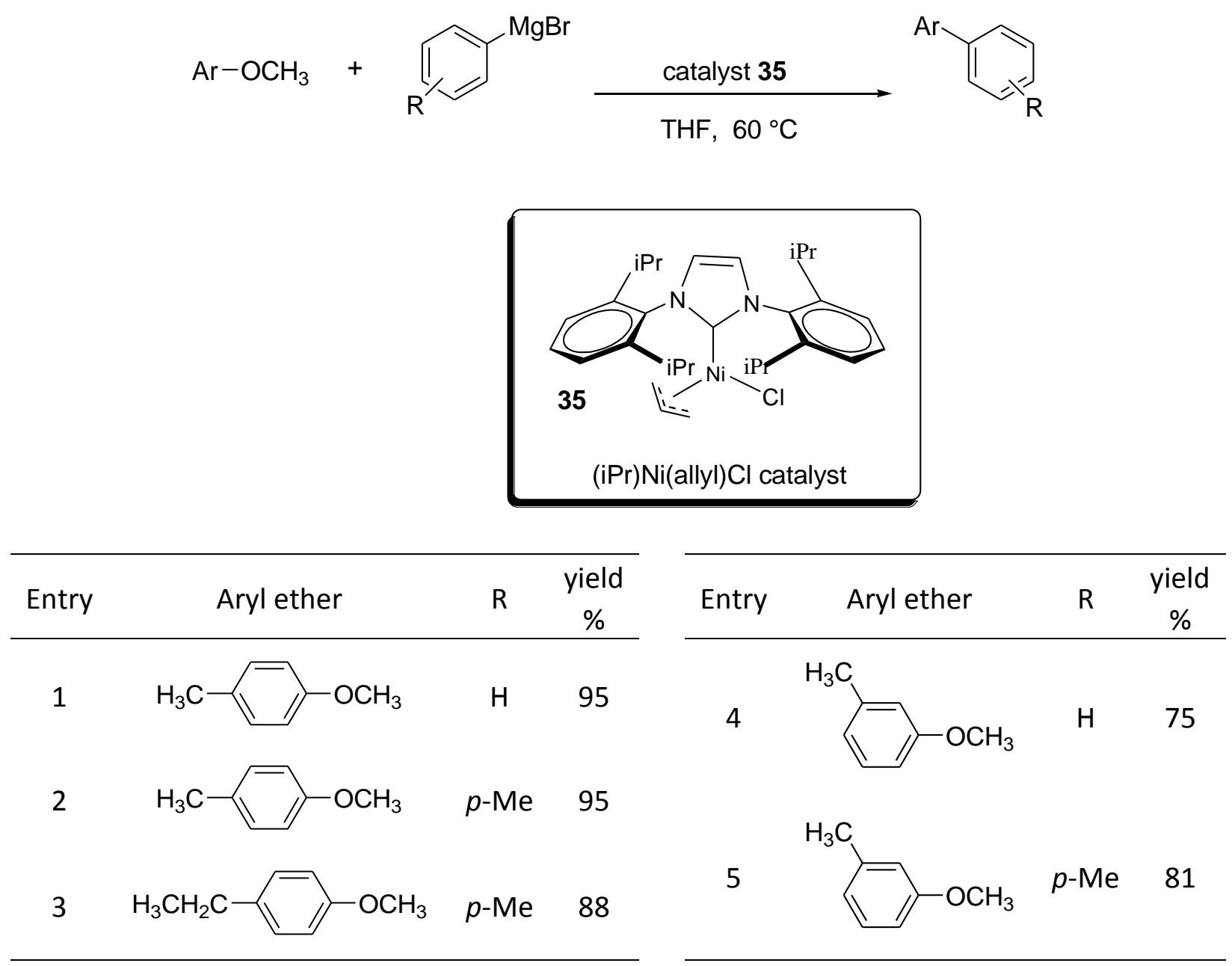

Scheme 16. Cross-coupling reaction of aryl ethers with $\mathrm{ArMgBr}$ catalyzed by (i-Pr)Ni(allyl)Cl. 
Aryl ethers are considered one of the most attractive substrates in terms of availability, cost, and safety. However, it is difficult to use aryl ethers in catalytic cross-coupling reactions because of the robust nature of the $\mathrm{C}\left(\right.$ aryl)-O bonds. ${ }^{69,70}$ Iglesias and Prieto have demonstrated an efficient protocol for the coupling reaction of $\mathrm{ArOCH}_{3}$ substrates and various aryl Grignard reagents in the presence of $5 \mathrm{~mol} \%$ of $(\mathrm{IPr}) \mathrm{Ni}(\mathrm{allyl}) \mathrm{Cl}$ as the catalyst. ${ }^{71} p$-Methyl and $p$-ethyl anisole substrates exhibited a high reactivity, hence the corresponding coupled products were obtained in excellent yields (Scheme 16) (entries 1-3), but $m$-methylanisole reacted with arylmagnesium bromides to afford only fair yields of the cross-coupled products (entries 4,5 ).

As mentioned earlier, the use of alkenyl and aryl fluorides as the coupling substrates in Kumada crosscoupling reactions has attracted much attention. ${ }^{72,73}$ Nakamura et al. made a distinct contribution to the development of coupling reactions of aryl fluorides with arylmagnesium bromides by virtue of the nickelhydroxyphosphine complex / Grignard system. ${ }^{74}$ This process might accelerate the oxidative addition of aryl halide substrates such as fluorides, chlorides, polyfluorides, and polychlorides. Kumada cross-coupling reactions of several aryl fluorides and $\mathrm{PhMgBr}$ could even be carried out smoothly at room temperature using $\mathrm{Ni}(\text { acac })_{2}$ as a satisfactory catalyst (Scheme 17). Aryl fluoride substrates with electron donating groups such as 4-methoxy or 4-dimethylamino furnished the coupled products in good yields with 1 mol\% catalyst loading (entries 1, 2). $\mathrm{Ni}(\mathrm{acac})_{2}$ catalyzed the arylation of polyfluorinated aromatics in the presence of a hydroxyphosphine ligand to transform $o$ - and $p$-difluorobenzenes into the corresponding terphenyls by using nearly stoichiometric amounts of $\mathrm{PhMgBr}$. The reaction of $p$-difluorobenzene was the fastest due to low steric hindrance, forming the required product in 92\% yield within 1 hour (entries 3, 4). Triarylation of 1,3,5trifluorobenzene with 3.5 equiv of the aryl Grignard reagent occurred in $88 \%$ yield (entry 5 ).

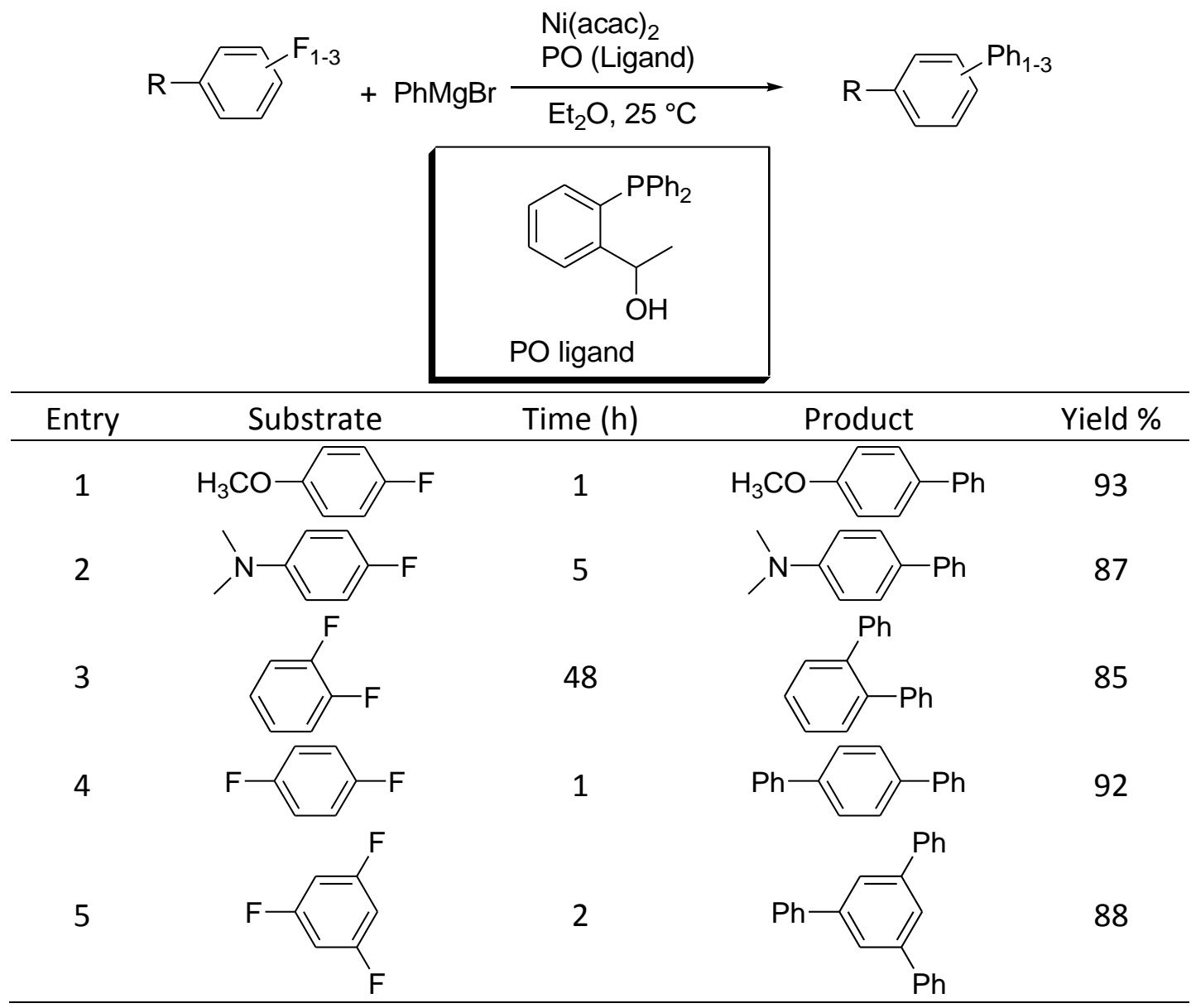

Scheme 17. Ni/PO-Catalyzed cross coupling of aryl fluorides (Ar-F) or aromatic polyfluorides and PhMgBr. 
Cárdenas and his group demonstrated an efficient and fast Kumada-Tamao-Corriu cross-coupling reaction at low temperatures with a low loading of $\mathrm{Ni}(\mathrm{acac})_{2}$ catalyst in the presence of diallyl ether as an essential additive. ${ }^{75}$ The cross-coupling reaction of $p$-methoxybenzyl chloride 36 and $n$ - $\mathrm{BuMgBr}$ at ${ }^{-30}{ }^{\circ} \mathrm{C}$ generated high yields up to $99 \%$ of the desired cross-coupled product 37 (Scheme 18).

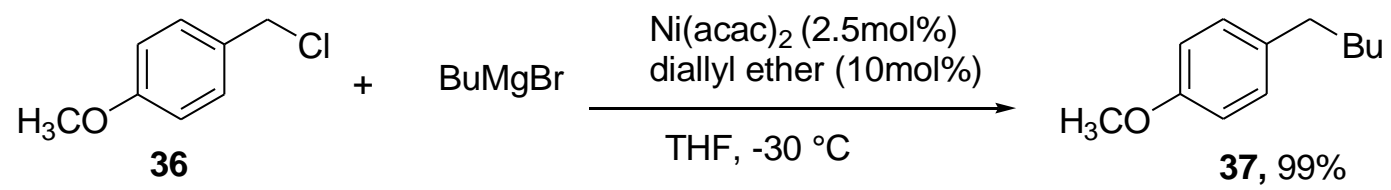

Scheme 18. Reaction of $p$-methoxybenzyl chloride with $\mathrm{n}-\mathrm{BuMgBr}$ at ${ }^{-3} 0^{\circ} \mathrm{C}$.

Electrophiles such as vinyl phosphates can undergo useful Kumada-Tamao-Corriu cross-coupling reactions which is a powerful tool for the cross coupling of enolized ketones. Thus, in 2018, Mazet et al. described a novel method to form 2-substituted 1,3-dienes $\mathbf{4 0}$ via coupling reaction between vinyl phosphate substrates 38 and vinyl magnesium bromide 39, with a nickel catalyst loading as low as $2.5 \mathrm{~mol} \%$, at room temperature (Scheme 19). ${ }^{76}$ This cross-coupling protocol tolerates a broad range of functional groups and permits the synthesis of substituted conjugated 1,3-dienes in high yield from alkenyl Grignard reagents and substituted enol phosphates (40a-40d).
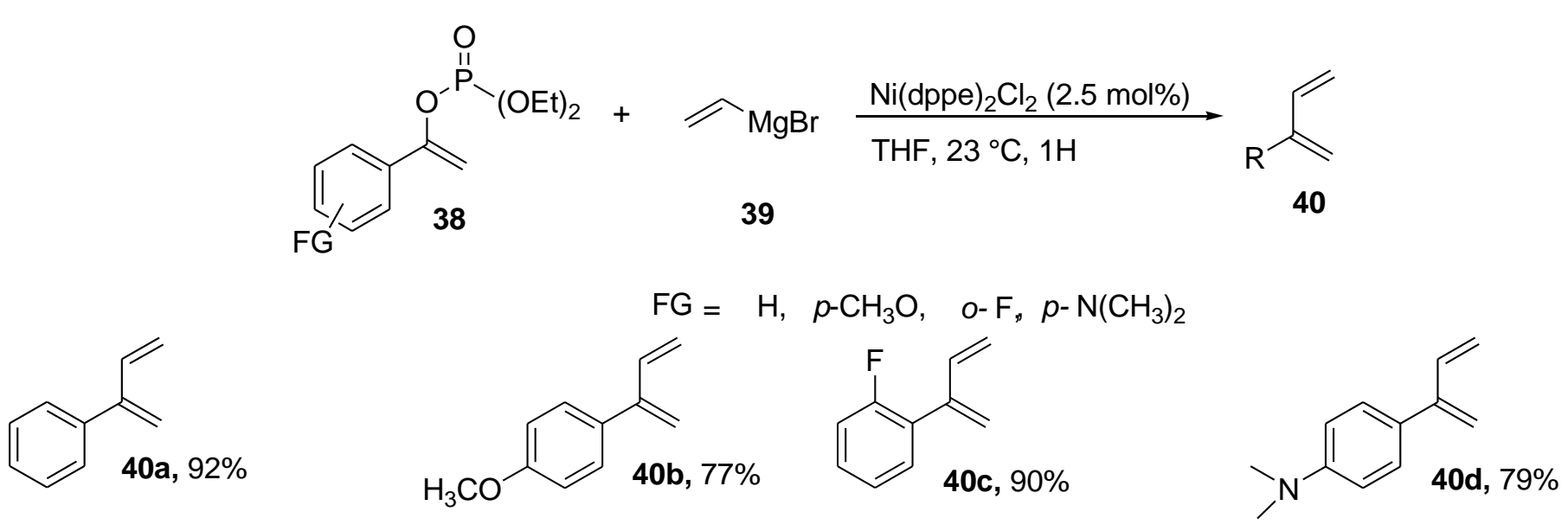

Scheme 19. The cross coupling reaction between diethyl (1-phenylvinyl) phosphate (38) and vinyl magnesium bromide (39) forming 2-substituted 1,3-dienes (40a-d).

\section{Conclusions}

The metal catalyzed Kumada-Tamao-Corriu cross-coupling reactions provide one of the most straightforward protocols for the construction of various carbon-carbon bonds. This review highlights significant recent developments in palladium- and nickel-catalyzed Kumada-Tamao-Corriu cross-coupling reactions to produce a wide variety of organic compounds. Considerable effort has been devoted to developing novel and efficient methods using palladium and nickel catalysts for the Kumada cross-coupling reaction of various organic halide substrates or related electrophiles with functionalized Grignard reagents or other metal organyls and significant achievements have emerged during the past decade. Palladium and nickel catalysts have enabled 
the coupling reaction of not only electronically deactivated substrates, but also sterically hindered substrates with various Grignard reagents to construct carbon-carbon bonds. This has had a notable impact on research and its employment in a variety of synthetic endeavors.

\section{References}

1. Jana, R.; Pathak, T. P.; Sigman, M. S, Chem. Rev. 2011, 111, 1417-1492.

http://dx.doi.org/10.1021/cr100327p

2. Terao, J.; Todo, H.; Watanabe, H.; Ikumi, A.; Kambe, N. Angew. Chem. Int. Ed. 2004, 43, 6180-6182. http://dx.doi.org/10.1002/anie.200460246

3. Vechorkin, O.; Hu, X. Angew. Chem. Int. Ed. 2009, 48, 2937-2940. http://dx.doi.org/10.1002/anie.200806138

4. Molnar. A. Chem. Rev. 2011, 111, 2251-2320. http://dx.doi.org/10.1021/cr100355b

5. Evano, G.; Blanchard, N.; Toumi, M. Chem. Rev. 2008, 108, 3054-3131. http://dx.doi.org/10.1021/cr8002505

6. Cahiez, G.; Moyeux, A. Chem. Rev. 2010. 110. 1435-1462.

http://dx.doi.org/10.1021/cr9000786

7. Chodkiewicz, W.; Cadiot, P. C. R. Hebd. Seances Acad. Sci. 1955, 241, 1055-1057.

8. Eglinton, G.; Galbraith, A. R. J. Chem. Soc. 1959, 889-896. http://dx.doi.org/10.1039/JR9590000889

9. Stephens, R. D.; Castro, C. E. J. Org. Chem. 1963, 28, 3313-3315. http://dx.doi.org/10.1021/jo01047a008

10. Tamao, K.; Sumitani, K.; Kumada. M. J. Am. Chem. Soc. 1972, 94, 4374-4376. http://dx.doi.org/10.1021/ja00767a075

11. Heck, R. F.; Nolley, J. P. J. Org. Chem. 1972, 37, 2320-2322.

http://dx.doi.org/10.1021/jo00979a024

12. Sonogashira, K.; Tohda, Y.; Hagihara, N. Tetrahedron Lett. 1975, 16, 4467-4470. http://dx.doi.org/10.1016/S0040-4039(00)91094-3

13. Panda, B.; Sarkar, T. K. Synthesis 2013, 45, 817-829. http://dx.doi.org/10.1055/s-0032-1318119

14. King, A. O.; Okukado, N.; Negishi, E. J. Chem. Soc. Chem. Commun. 1977, 683-684. http://dx.doi.org/10.1039/C39770000683

15. Luzung, M. R.; Patel, J. S.; Yin, J. J. Org. Chem. 2010, 75, 8330-8332. http://dx.doi.org/10.1021/jo1018798

16. Milstein, D.; Stille, J. K. J. Am. Chem. Soc. 1978, 100, 3636-3638. http://dx.doi.org/10.1021/ja00479a077

17. Milstein, D.; Stille J. K. J. Am. Chem. Soc. 1979, 101, 4992-4998. http://dx.doi.org/10.1021/ja00511a032

18. Miyaura, N.; Yamada, K.; Suzuki, A. Tetrahedron Lett. 1979, 20, 3437-3440. http://dx.doi.org/10.1016/S0040-4039(01)95429-2

19. Littke, A. F.; Fu, G. C. Angew. Chem. Int. Ed. 2002, 41, 4176-4211. http://dx.doi.org/10.1002/1521-3773(20021115)41:22<4176::AID-ANIE4176>3.0.CO;2-U

20. Miyaura, N.; Suzuki, A. Chem. Rev. 1995, 95, 2457-2483. 
http://dx.doi.org/10.1021/cr00039a007

21. Hatanaka, Y.; Hiyama, T. J. Org. Chem. 1988, 53, 918-920.

http://dx.doi.org/10.1021/j000239a056

22. Tang, S.; Takeda, M.; Nakao, Y.; Hiyama. T. Chem. Commun. 2011, 47, 307-309.

http://dx.doi.org/10.1039/COCC02173C

23. Hiyama, T.; Hatanaka, Y. Pure Appl Chem. 1994, 66, 1471-1478.

http://dx.doi.org/10.1351/pac199466071471

24. Tokuyama, H.; Yokoshima, S.; Yamashita, T.; Fukuyama, T. Tetrahedron Lett. 1998, 39, 3189-3192. http://dx.doi.org/10.1016/S0040-4039(98)00456-0

25. Tokuyama, H.; Yokoshima, S.; Lin, S.; Li, L.; Fukuyama, T. Synthesis 2002, 8, 1121-1123. http://dx.doi.org/10.1055/s-2002-31969

26. Liebeskind, L.; Srogl, J. J. Am. Chem. Soc. 2000, 122, 11260-11261.

http://dx.doi.org/10.1021/ja005613q

27. Labinger. J. Organometallics 2015, 34, 4784-4795.

http://dx.doi.org/10.1021/acs.organomet.5b00565

28. Polet, D.; Alexakis, A. Org. Lett. 2005, 7, 1621-1624.

http://dx.doi.org/10.1021/ol050350w

29. Farina, V.; Krishnan, B. J. Am. Chem. Soc. 1991, 113, 9585-9595.

http://dx.doi.org/10.1021/ja00025a025

30. Hartwig, J. F.; Stanley, L. M. Acc. Chem. Res. 2010, 43, 1461-1475.

http://dx.doi.org/10.1021/ar100047x

31. Tasker, S.; Standley, E.; Jamison, T. Nature 2014, 509, 299-309.

http://dx.doi.org/10.1038/nature13274

32. Cornella, J.; Gómez-Bengoa, E.; Martin, R. J. Am. Chem. Soc, 2013, 135, 1997-2009.

http://dx.doi.org/10.1021/ja311940s

33. Hayashi, T.; Konishi, M.; Kobori, Y.; Kumada, M.; Higuchi, T.; Hirotsu, K. J. Am. Chem. Soc. 1984, 106, 158163.

http://dx.doi.org/10.1021/ia00313a032

34. Moher, J.; Krout, M.; Stoltz, B. Nature 2008, 455, 323-332.

http://dx.doi.org/10.1038/nature07370

35. Luo, X.; Zhang, H.; Duan, H.; Liu, Q.; Zhu, L.; Zhang, T.; Lei, A. Org Lett. 2007, 9, 4571-4574. http://dx.doi.org/10.1021/ol701995t

36. Ben-David, Y.; Portnoy, M.; Gozin, M.; Milstein, D. Organometallics 1992, 11, 1995-1996. http://dx.doi.org/10.1021/om00042a008

37. Dahadha, A.; Imhof, W. Arkivoc 2013, (iv), 200-216.

http://dx.doi.org/10.3998/ark.5550190.p008.044

38. Trost, B. M. Tetrahedron 1977, 33, 2615-2649. http://dx.doi.org/10.1016/0040-4020(77)80284-6

39. Fernández-Rodríguez, M.; Hartwig, J. J. Org. Chem. 2009, 74, 1663-1672. http://dx.doi.org/10.1021/j0802594d

40. Kumar, A.; Kumar Rao, G.; Kumar, S.; Singh, A. Organometallics 2014, 33, 2921-2943. http://dx.doi.org/10.1021/om4007196

41. Hu, X. Chimia, International Journal for Chemistry 2010, 64, 231-234. http://dx.doi.org/10.2533/chimia.2010.231 
42. Yonova, I.; Johnson, A.; Osborne, C.; Moore, C. Angew. Chem. 2014, 53, 2422-2427. http://dx.doi.org/10.1002/anie.201308666

43. Galardon, E.; Ramdeehul, S.; Brown, J. M.; Cowley, A.; Hii, K. K.; Jutand, A. Angew.Chem. 2002, 41, 17601763.

http://dx.doi.org/10.1002/1521-3773(20020517)41:10<1760::AID-ANIE1760>3.0.CO;2-3

44. Molander, G.; Canturk, B. Angew. Chem. 2009, 48, 9240-9261.

http://dx.doi.org/10.1002/anie.200904306

45. Denmark, S. E.; Regens, C. S. Acc. Chem. Res. 2008, 41, 1486-1499.

http://dx.doi.org/10.1021/ar800037p

46. Cacchi, S.; Fabrizi, G.; Goggiamani, A. Adv. Synth. Catal. 2006, 348, 1301-1305.

http://dx.doi.org/10.1002/adsc.200606060

47. Old, D. W.; Wolfe, J. P.; Buchwald, S. L. J. Am Chem Soc, 1998, 120, 9722-9723.

http://dx.doi.org/10.1021/ja982250

48. Martin, R.; Buchwald, S. L. Acc Chem Res. 2008, 41, 1461-1473.

http://dx.doi.org/10.1021/ar800036s

49. Huang, J.; Nolan. S. J. Am. Chem. Soc. 1999, 121, 9889-9890.

http://dx.doi.org/10.1021/ja991703n

50. Vechorkin, O.; Proust, V.; Hu, X. J. Am. Chem. Soc. 2009, 131, 9756-9766.

http://dx.doi.org/10.1021/ja9027378

51. Terao, J.; Kambe, N. Acc. Chem. Res. 2008, 41, 1545-1554.

http://dx.doi.org/10.1021/ar800138a

52. Knochel, P.; Krasovskiy, A.; Sapountzis, I. Handbook of Functionalized Organometallics, Wiley-VCH, Weinheim, 2005, Vol. 1, pp. $109-172$.

53. Boymond, L.; Rottländer, M.; Cahiez, G.; Knochel, P. Angew. Chem. Int. Ed. 1998, 37, 1701-1703. http://dx.doi.org/10.1002/(SICI)1521-3773(19980703)37:12<1701::AID-ANIE1701>3.0.CO;2-U

54. Adrio, J.; Carretero, J. Chem. Cat. Chem. 2010, 2, 1384-1386.

http://dx.doi.org/10.1002/cctc.201000237

55. Martin, R.; Buchwald, S. L. J. Am. Chem. Soc. 2007, 129, 3844-3845.

http://dx.doi.org/10.1021/ja070830d

56. Krasovskiy, A.; Haley, S.; Voigtritter, K.; Lipshutz, B. Organic Lett. 2014, 16, 4066-4069.

http://dx.doi.org/10.1021/ol501535w

57. Krasovskiy, A.; Knochel, P. Angew. Chem. 2004, 43, 3333-3336.

http://dx.doi.org/10.1002/anie.200454084

58. Hua. X.; Makdissi, J.; Sullivan, R.; Newman, S. Organic Lett. 2016, 18, 5312-5315.

http://dx.doi.org/10.1021/acs.orglett.6b02631

59. Amii, H.; Uneyama, K. Chem. Rev. 2009, 109, 2119-2183.

http://dx.doi.org/10.1021/cr800388c

60. Dai, W.; Xiao, J.; Jin, G.; Wu, J.; Cao, S. J. Org. Chem. 2014, 79, 10537-10546.

http://dx.doi.org/10.1021/j05022234

61. Ivanov, S.; Boldyrev, I. Organic \& Biomolecular Chemistry 2014, 12, 6145-6150.

http://dx.doi.org/10.1039/C4OB01018C

62. Sugita, N.; Hayashi, S.; Hino, F.; Takanami, T. J. Org. Chem. 2012, 77, 10488-10497.

http://dx.doi.org/10.1021/jo302122f

63. Maruyama, K.; Katagiri, T. J. Phys. Org. Chem. 1989, 2, 205-213. 
http://dx.doi.org/10.1002/poc.610020303

64. Garst, J. F.; Ungvary, F. "Mechanism of Grignard reagent formation, In Grignard Reagents; Richey, R. S., Ed.; John Wiley \& Sons: New York, 2000; pp 185-275.

65. Rogers, H. R.; Hill, C. L.; Fujiwara, Y.; Rogers, R. J.; Mitchell, H. L.; Whitesides, G. M. J. Am. Chem. Soc. 1980, 102, 217-226.

http://dx.doi.org/10.1021/ja00521a034

66. Bhattacharjya, A.; Klumphu, P.; Lipshutz, B. Nature Commun. 2015, 6, 1-6.

http://dx.doi.org/10.1038/ncomms8401

67. Liu, N.; Wang, X. Z. J. Org. Chem. 2011, 76, 10031-10038.

http://dx.doi.org/10.1021/jo201821g

68. Zhang, X.; Wang, X. Z. Synlett 2013, 24, 2081-2084.

http://dx.doi.org/10.1055/s-0033-1339653

69. Tobisu, M.; Chatani, N. Acc. Chem. Res. 2015, 48, 1717-1726.

http://dx.doi.org/10.1021/acs.accounts.5b00051

70. Rosen, B. M.; Quasdorf, K. W.; Wilson, D. A.; Zhang, N.; Resmerita, M. A.; Garg, N. K.; Percec, V. Chem.

Rev. 2011, 111, 1346-1416.

http://dx.doi.org/10.1021/cr100259t

71. Iglesias, J. M.; Prieto, A.; Nicasio, M. Org. Lett. 2012, 14, 4318-4321.

http://dx.doi.org/10.1021/ol302112q

72. Yoshikai, N.; Mashima, H.; Nakamura, E. J. Am. Chem. Soc., 2005, 127, 17978-17979. http://dx.doi.org/10.1021/ja056327n

73. Han, J.; Zong, L.; Liu, C.; Wang, J.; Jian, X. Polymer International 2016, 65, 526-534. http://dx.doi.org/10.1002/pi.5086

74. Yoshikai, N.; Matsuda, H.; Nakamura, E. J. Am. Chem. Soc. 2009, 131, 9590-9599. http://dx.doi.org/10.1021/ja903091g

75. Yanes, R. S.; Ceinos, M. G.; Buñuel, E.; Cárdenas, D. J. Eur. J. Org. Chem. 2014, 2014, 6625-6629. http://dx.doi.org/10.1002/ejoc.201403007

76. Fiorito, D.; Folliet, S.; Liu, Y.; Mazet, C. ACS Catal. 2018, 8, 1392-1398.

http://dx.doi.org/10.1021/acscatal.7b04030

\section{Authors' Biographies}

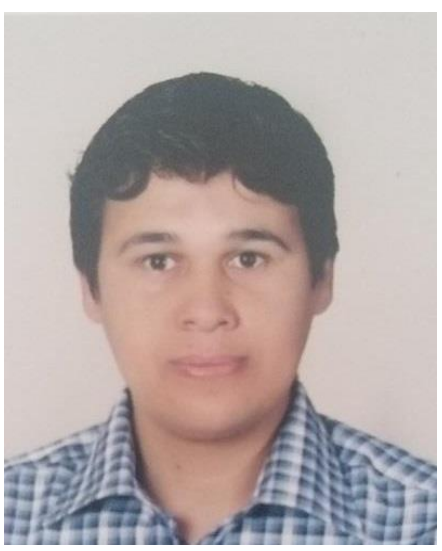

Adnan A. Dahadha was born in 1979 in Irbid, Jordan. He has received his B.Sc. and M.Sc. from Applied Chemistry Department, Faculty of Science, Jordan University of Science and Technology, Jordan. In 2012 he 
obtained his Ph.D. degree in Organic Chemistry from Friedrich Schiller University, Jena, Germany. He worked as an assistant professor at Department of Chemistry, Faculty of Science, Sattam bin Abdul-Aziz University, Saudi Arabia during the period 2013- 2015. Then, he appointed at Pharmacy Faculty, Philadelphia University, Jordan, Sept. 2015 - Aug. 2018. Currently, he is assistant professor of Organic Chemistry at Faculty of Science, Biotechnology Department, Philadelphia University, Jordan.

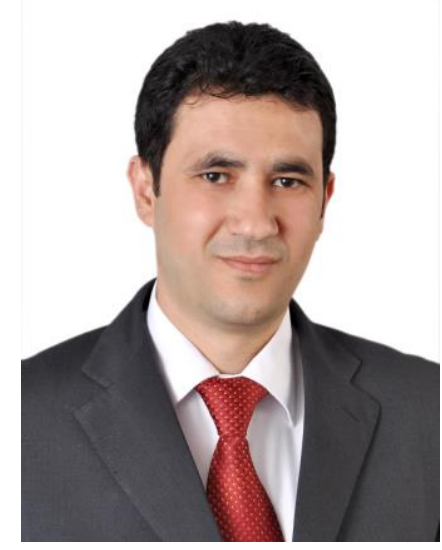

Mohammad M. Aldhoun was born in Irbid, Jordan, in 1975. He got his B.Sc in 1997 from Chemistry Department, Faculty of Science Yarmouk University, Jordan. He received his M.Sc. in 2001 from the same university. In 2009, he received his Ph.D. degree in Organic Chemistry, Ferrara University, Italy. Since 2009 until now, he is assistant professor of Organic Chemistry at Pharmacy Faculty, Philadelphia University, Amman, Jordan. 